\title{
Social aspects of leprosy: a case study in Zaria, Northern Nigeria
}

\author{
N B B REDDY, S K SATPATHY, $†$ S A R KRISHNAN \\ \& T SRINIVASAN \\ Leprosy Control, Training \& Research Centre, PMB 1089, Zaria, \\ Nigeria; †Department of Community Medicine, Ahmadu Bello \\ University, Zaria, Nigeria
}

\section{Accepted for publication 6 September 1984}

\begin{abstract}
Summary This is a study of the socio-economic impact of leprosy on a group of 129 patients under treatment in Zaria, Northern Nigeria, with additional notes on their views about leprosy, their reasons for delays in seeking medical advice, their expectations from Government, and the role of patients in a leprosy control programme.
\end{abstract}

\section{Introduction}

Leprosy holds a unique position among communicable diseases because of the incidence of deformity, physical handicap, and ostracism due to social stigma. The attitude of patients to leprosy control is influenced by widely held traditional beliefs about the disease and its causes, and it is important for those engaged in leprosy work to be informed about social aspects. The objectives of this study were to learn about the socio-economic effects of the disease and to discover what views were held about leprosy and its causes.

\section{Materials and methods}

A cross-sectional study was conducted in 29 leprosy clinics of Zaria Local Government Area between September 1983 and January 1984, where 1556 leprosy patients were registered in a population of approximately 667,000. A systematic sample was taken (every 10th patient amongst those above 15 years of age) consisting of 129 patients over the age of 15 years, with 84 males and 45 females. Ninety-three were in the age group 15-44 years, and 36 were 45 years or above. All 129 patients were interviewed according to a pre-designed and pre-tested schedule. 


\section{Results}

(1) Personal characteristics. The majority belonged to the Hausa tribe and were Muslims. Their standard of education was low, as was their socio-economic status. Sixty-three had one or more deformities.

(2) Socio-economic impact of leprosy. (a) Migration. Of the 33 patients who migrated to Zaria, 21 did so for reasons directly connected with their disease: the majority did so in order to be near a treatment centre, and a very small minority migrated because they were not wanted in the family or in order to beg. (b) Effect on occupation. Apart from 7 who resorted to begging, the remainder continued in their way of life, whether as agriculturalists, petty traders, etc. The few employed persons were able to continue in employment, although in some cases the employers objected to their deformities and had to be persuaded to allow them to continue in work. (c) Effect on income. The majority suffered only a marginal reduction in income, but 43 lost one-half to two-thirds of their income, and 8 became paupers and either resorted to begging or to being sustained by their families. (d) Effect on marital and family life. Of the 129 patients interviewed, 82 were living married lives, 16 were divorced ( 10 males and 6 females), 13 were living alone although married, 2 had become widowers, and 16 were still unmarried. Eleven of those leading married lives said that their disease was responsible for lack of harmony, making a total of 40 who had marriage problems. As regards the effect of leprosy on family life, 18 had experienced worsenıng.

(3) Patients' views on leprosy. Apart from 10 patients, all the remainder accepted that they were suffering from leprosy. As to causes of leprosy, 46 held supernatural causes responsible, 31 blamed poor living conditions, 9 blamed contact with leprosy sufferers, 4 mentioned germs, and the remainder said they did not know. On the subject of curability, 78 believed leprosy to be curable, 31 believed it to be partially curable, 3 had no faith in cure, and 17 did not know.

(4) Delays in seeking medical advice. Although there was an average delay of $1 \frac{1}{2}$ years between onset of symptoms and seeking medical advice, 73 delayed for 4 or more years. Illiterate patients had the longest delays. Reasons for delay were: the taking of traditional medicine $(47 \%)$; ignorance $(31 \%)$; belief in self-healing $(6 \%)$, and non-availability of diagnostic services $(16 \%)$.

(5) Expectations from Government. When asked if they expected more from Government, 81 answered in the affirmative; 48 wanted more effective medicine, 24 wanted more clinics and leprosy workers, 3 expected financial help, 3 expected jobs, 2 thought that hospital transport should be provided, and 1 wanted food to be provided. Twenty-seven did not expect more from Government, and 21 had no ideas to express.

(6) The role of patients in leprosy control. When the 129 patients were asked what role they could play in leprosy control, 25 said that if they came across untreated leprosy sufferers they would advise them to report for treatment, 21 
wanted to educate the public about leprosy, 6 said they would bring family contacts for medical examination, 1 patient wanted to donate money to the clinic, and 1 young man wanted to become a doctor in order to treat leprosy, but 24 were quite negative about their role, and 51 did not know what they could do.

\section{Discussion}

The majority of patients interviewed in this study had a low educational and socio-economic status, suffered no social ostracism because of their disease and were able to continue their various occupations, but had to accept a reduced income due largely to physical handicap from deformity and to phases of lepra reactions. Nearly $50 \%$ had one or more deformities. A minority experienced marital disruption due to their leprosy, and one-half of those leading married lives had marriage problems. One-third of the group believed that their leprosy was due to supernatural causes, and nearly two-thirds believed that the disease could be cured. The main reason for delay in diagnosis and treatment was the time spent receiving ineffective treatment from traditional practitioners, and consideration should be given to the proposition that such practitioners should be given training in the diagnosis and treatment of leprosy. The need for more effective chemotherapy, expressed by more than one-third of the group, will be met by the introduction of multidrug therapy. 